\title{
An assessment of Irish farmers' knowledge of the risk of spread of infection from animals to humans and their transmission prevention practices
}

\author{
M. M. MAHON ${ }^{1}$, M. C. SHEEHAN ${ }^{2}$, P. F. KELLEHER ${ }^{3}$, A. J. JOHNSON ${ }^{4}$ AND \\ S. M. DOYLE ${ }^{1}$ \\ ${ }^{1}$ Department of Public Health, Health Service Executive South East, Lacken, Dublin Road, Kilkenny, Ireland \\ ${ }^{2}$ Kilkenny Regional Veterinary Laboratory, Hebron Road, Kilkenny, Ireland \\ ${ }^{3}$ Department of Agriculture Food and the Marine, Veterinary Public Health, PO Box 149, Carlow, Ireland \\ ${ }^{4}$ Limerick Regional Veterinary Laboratory, Knockalisheen, Limerick, Ireland
}

Received 2 February 2017; Final revision 14 June 2017; Accepted 14 June 2017; first published online 10 July 2017

\section{SUMMARY}

The aim of this study was to ascertain farmers' knowledge of the risk of spread of infection from animals to humans, and their transmission prevention practices. This was a survey of farmers who submitted material to Ireland's Regional Veterinary Laboratories in 2015. There was an $84 \%$ response rate (1044 farmers). Ninety per cent of farmers were not aware that infection can be acquired from apparently healthy animals. Over half were not aware that disease could be contracted from sick poultry or pets. Conversely, the knowledge of the risk to pregnant women of infection from birthing animals was high $(88 \%)$. Four-fifths of farmers sourced drinking water from a private well, and of these, $62 \%$ tested their water less frequently than once a year. Of dairy farmers, $39 \%$ drank unpasteurised milk once a week or more frequently. Veterinarians were the most commonly cited information source for diseases on farms. The survey findings indicate that the level of farmers' knowledge and awareness of the spread of infection from animals to humans is a concern. Further education of the farming community is needed to increase awareness of both the potential biohazards present on farms and the practical measures that can be taken to mitigate the risk of zoonoses.

Key words: Farmers, infection prevention, infection control, knowledge, zoonoses.

\section{INTRODUCTION}

Ireland, with its rich fertile soils and mild moist climate is well suited to farming and, according to the Census of Agriculture, 2010, almost two thirds of the land area of the country is used for agriculture [1]. Beef and milk production account for over half of all agricultural output. Sheep, pig, poultry and tillage

\footnotetext{
* Author for correspondence: M. Mahon, Department of Public Health, Health Service Executive South East, Lacken, Dublin Road, Kilkenny, R95 P231, Ireland.

(Email: marrita.mahon@hse.ie)
}

farming are also important [1]. Regionally, the Border-Midland-West region has a higher proportion of specialist sheep and specialist beef production, compared with the South East region, where specialist tillage and specialist dairying tend to dominate. In 2010, the regular farm workforce was made up of approximately 140000 farm holders, 41000 spouses, 70000 family members and 16000 regular non-family workers. Eighty-seven per cent of the farm holders were male, with an average age of 54 years. The average age of the female farm holders was 58 years [1].

Infections that are naturally transmissible from vertebrate animals to humans are known as zoonoses [2]. 
Previous studies have suggested that veterinarians encounter zoonotic diseases more frequently than physicians [3], and that farmers felt that family doctors' knowledge of zoonotic diseases was poor [4]. The One Health approach recognises that the health of people is connected to the health of animals and the health of the environment. The goal of One Health is to encourage collaboration between human, animal and environmental health entities in surveillance, outbreak response and prevention, to achieve an optimal human health outcome [5]. This is important because, of all human pathogens $60 \%$ are zoonotic [6].

Zoonoses are transmitted by ingestion, bite, scratch, inhalation or skin contact. Indirect transmission of zoonotic gastrointestinal pathogens has been documented in outbreak settings, with illness being associated with contact with contaminated clothing or shoes, animal bedding, flooring, barriers and other environmental surfaces [7]. Farmers, because of their work with livestock, in an environment often contaminated with animal faeces or by-products, may be at higher risk for zoonotic disease. Other members of farming households, even if not working on the farm, may also be at higher risk through their direct and indirect contact with animals. Consistent, thorough hand hygiene is the single most important measure that can be taken to reduce the risk of disease transmission [8], most particularly gastrointestinal infections, but also respiratory tract and skin infections [9].

Consumption of unpasteurised milk or untreated water may also put farmers and their families at risk of contracting zoonotic infection. Unpasteurised (raw) milk can carry harmful bacteria such as Campylobacter, Listeria, Brucella, Mycobacterium bovis, Salmonella, or Verotoxigenic Escherichia coli (VTEC) [10]. The significant infection risks associated with the consumption of raw milk or raw milk derived products are well documented internationally [11-13]. The Central Statistics Office (CSO) reported that, in $2011,48 \%$ of Irish agricultural households get water from a private source [14]. This contrasts with private well ownership in Ireland generally, which was $11 \%$ in 2011 [15]. Well water can be vulnerable to contamination, particularly if the well is not properly constructed or protected [16]. Human cases of Cryptosporidiosis and VTEC are legally notifiable in Ireland [17]. Nationally, cases with private wells are consistently, statistically significantly, overrepresented among cases of both Cryptosporidiosis and VTEC [18]. In 2014, $25 \%$ and $32 \%$ of human cases of
Cryptosporidiosis and VTEC cases, respectively, reported consuming water from a private well source [19]. The Environmental Protection Agency (EPA) has reported that $25 \%$ of groundwater supplies in Ireland are contaminated with faecal coliforms [20].

The South East Regional Zoonoses Committee (SERZC) is a multi-agency group comprising human and animal-health professionals from the South East of Ireland. Members include doctors, scientists, environmental health officers and veterinarians. The SERZC undertakes health education and promotion activities throughout the year. One group which is an important target audience for the committee is farmers.

The six Regional Veterinary Laboratories (RVLs), sited across the country, provide a national, subsidised clinical pathology, and post-mortem diagnostic service to farmers, through referral by their private veterinary practitioners. Farmers attending the RVLs to submit material do so to diagnose animal health problems on their farm. A subgroup of the SERZC decided to conduct a survey of these farmers, with the following objectives: to determine farmers' knowledge of zoonoses, and of the risk of infection posed to humans by some common animal exposures; to determine whether (and how often) farmers carry out simple infection prevention activities on their farms; and to find out where farmers get information on diseases, to inform future health promotion activities. To our knowledge it is the first survey of its kind in Europe.

\section{METHODS}

An anonymous survey of people who presented at the six Irish RVLs, located in Athlone, Cork, Dublin, Kilkenny, Limerick and Sligo was undertaken between February and June 2015. The director of each RVL was briefed on the questionnaire by an author and they explained the meaning of each question to their staff. Administrative staff at each RVL aimed to request consecutive persons, who presented to submit material for examination at the RVLs, to complete the survey questionnaire. Each potential respondent was asked if they had previously completed the questionnaire, and if so it was not re-offered to them. Administrative or professional staff at each laboratory were available to those completing the survey, to answer queries about the meaning of the survey questions. They did not assist in answering questions.

The self-administered pen-and-paper questionnaires, consisting of 22 closed, partially closed and 
Table 1. Aspects of farmers' knowledge of the risk of zoonotic infection and their transmission prevention practices addressed by the Farmer Survey questionnaire listed by topic and question type

\begin{tabular}{|c|c|}
\hline Aspect & Detail $^{\mathrm{a}}$ \\
\hline 1. Farmer characteristics & $\begin{array}{l}\text { Gender (c); age (o); type of farm (pc); regional veterinary laboratory } \\
\text { attended (c) }\end{array}$ \\
\hline 2. Knowledge of infection & $\begin{array}{l}\text { What is a zoonosis (c); can a farmer or a family member get an infection } \\
\text { from scouring animals, aborting animals, sick poultry, pets, healthy } \\
\text { animals (c); can a child get gastroenteritis from being around animals (c); } \\
\text { is it safe for a pregnant woman to attend birthing animals (c) }\end{array}$ \\
\hline 3. Farm hygiene & $\begin{array}{l}\text { Are hands washed before eating or smoking }(\mathrm{c}) \text {; when are hands washed } \\
\text { during the working day (c); when is personal protective clothing worn } \\
\text { (c); when are disposable gloves worn (pc) }\end{array}$ \\
\hline 4. Drinking water supply to the home & $\begin{array}{l}\text { What type of water supply services the family home (c); how often is } \\
\text { private well water microbiologically tested (c) }\end{array}$ \\
\hline 5. Consumption of unpasteurised milk & Frequency of consumption of unpasteurised milk (c) \\
\hline 6. Information sources for farm diseases & Where do farmers source information on farm diseases (c) \\
\hline
\end{tabular}

${ }^{\mathrm{a}} \mathrm{c}$, closed-ended; o, open-ended; pc, partially closed-ended question.

open questions, were devised by veterinary, medical and scientific members of the SERZC. The questions are summarised in Table 1. The questionnaire was pilot-tested on 39 people who attended Kilkenny RVL during the first week of February, 2015. They all completed the survey in $<5 \mathrm{~min}$.

This was a cross-sectional survey. Survey responses were entered into an author-designed Excel spreadsheet by an RVL administrator. The data was validated and cleaned in Excel by one of the authors, before being copied to IBM SPSS Statistics (SPSS Inc, Chicago) Version 22, which was used to recode variables and to calculate proportions, odds ratios (ORs) and significance values. Data were collapsed into dichotomous variables as per Tables 3-5 for the calculation of ORs. Associations were determined between variables such as age, specialist farming type, knowledge and behaviour. Gender could not be examined as there were so few female farmers. Respondents did not always answer all the questions; for the questions on knowledge of infection, missing data were considered not being able to answer the question, for all other questions, missing data were excluded and available-case analysis was used.

\section{RESULTS}

\section{Study sample and demographics}

In total, 1242 persons who presented at the six RVLs between February and June 2015 were requested to complete the survey. There was a response rate of $84 \%$, giving a final sample size of 1044 . The age of the respondents ranged from 12 to 91 years, with a mean age of 46 years (Fig. 1). More than $90 \%$ were male (Fig. 1, Table 1). Responses were received from each of the six RVLs in Ireland; however, more responses were received from the laboratories servicing farmers in the Midlands/North (Athlone), South East (Kilkenny), West/South West (Limerick) and West/North West (Sligo) than those servicing the South (Cork) and the East (Dublin) (Table 2). There was a variety of farming types reported. While more than half $(57 \%)$ practised only one type, many farmers practised more than one type of farming (Table 2).

\section{Knowledge of zoonoses and risk of infection from animals}

Respondents' answers to questions probing knowledge of zoonoses and the risk of infection from animals, and comparisons between younger and older farmers and specialist dairy and specialist suckler farmers are shown in Table 3. Two-thirds of respondents were unaware that a zoonosis is a disease a person gets from an animal, while $90 \%$ did not know that healthy animals may be a source of infection for themselves or family members. Almost $80 \%$ of farmers identified aborting cows, ewes or sows as potential sources of infection and $88 \%$ knew that it is not safe for pregnant women to help birthing animals. Younger farmers $(<45$ years) were more likely than older farmers $(45+$ years) to know what a zoonosis is, that one can catch an infection from healthy 
Table 2. Characteristics of respondents in the Farmer Survey

\begin{tabular}{|c|c|c|c|c|c|}
\hline & Respondents $(N)$ & & Number & Percentage & $95 \% \mathrm{CI}^{\mathrm{a}}$ \\
\hline \multirow[t]{2}{*}{ Gender } & 889 & Male & 815 & $91 \cdot 7$ & $89 \cdot 7-93 \cdot 3$ \\
\hline & & Female & 74 & $8 \cdot 3$ & $6 \cdot 7-10 \cdot 3$ \\
\hline \multirow[t]{2}{*}{ Age group } & 982 & $<45$ years & 440 & $44 \cdot 8$ & $41 \cdot 7-47 \cdot 9$ \\
\hline & & $45+$ years & 542 & $55 \cdot 5$ & $52 \cdot 1-58 \cdot 3$ \\
\hline \multirow[t]{6}{*}{ RVL attended } & 1044 & Athlone & 299 & $28 \cdot 6$ & $26 \cdot 0-31 \cdot 5$ \\
\hline & & Cork & 92 & $8 \cdot 8$ & $7 \cdot 2-10 \cdot 7$ \\
\hline & & Dublin & 18 & $1 \cdot 7$ & $1 \cdot 1-2 \cdot 7$ \\
\hline & & Kilkenny & 263 & $25 \cdot 2$ & $22 \cdot 7-27 \cdot 9$ \\
\hline & & Limerick & 211 & $20 \cdot 2$ & $18 \cdot 0-22 \cdot 8$ \\
\hline & & Sligo & 161 & $15 \cdot 4$ & $13 \cdot 4-17 \cdot 7$ \\
\hline \multirow{7}{*}{ Farming type $^{\mathrm{b}}$} & 1031 & Dairy & 438 & $42 \cdot 5$ & $39 \cdot 5-45 \cdot 5$ \\
\hline & & Suckler & 486 & $47 \cdot 1$ & $44 \cdot 1-50 \cdot 2$ \\
\hline & & Beef & 339 & $32 \cdot 9$ & $30 \cdot 1-35 \cdot 8$ \\
\hline & & Sheep & 270 & $26 \cdot 2$ & $23 \cdot 6-29 \cdot 0$ \\
\hline & & Pigs & 12 & $1 \cdot 1$ & $0 \cdot 7-2 \cdot 0$ \\
\hline & & Poultry & 27 & $2 \cdot 6$ & $1 \cdot 8-3 \cdot 8$ \\
\hline & & Other & 43 & $4 \cdot 2$ & $3 \cdot 1-5 \cdot 6$ \\
\hline \multirow{7}{*}{ Specialist farming type ${ }^{\mathrm{c}}$} & 592 & Dairy & 266 & $44 \cdot 9$ & $41 \cdot 0-49 \cdot 0$ \\
\hline & & Suckler & 220 & $37 \cdot 2$ & $33 \cdot 3-41 \cdot 1$ \\
\hline & & Beef & 44 & $7 \cdot 4$ & $5 \cdot 6-9 \cdot 8$ \\
\hline & & Sheep & 56 & $9 \cdot 4$ & $7 \cdot 4-12 \cdot 1$ \\
\hline & & Pigs & 2 & $0 \cdot 3$ & $0 \cdot 09-1 \cdot 2$ \\
\hline & & Poultry & 1 & $0 \cdot 2$ & $0 \cdot 03-0 \cdot 95$ \\
\hline & & Other & 3 & $0 \cdot 5$ & $0 \cdot 002-1 \cdot 4$ \\
\hline \multirow{4}{*}{ Drinking water supply to the home ${ }^{b}$} & 1036 & Public & 242 & $23 \cdot 4$ & $20 \cdot 9-26 \cdot 0$ \\
\hline & & Private Well & 611 & $59 \cdot 0$ & $56 \cdot 0-61 \cdot 9$ \\
\hline & & Private group water scheme & 131 & $12 \cdot 6$ & $10 \cdot 8-14 \cdot 8$ \\
\hline & & Public group water scheme & 80 & $7 \cdot 7$ & $6 \cdot 2-9 \cdot 5$ \\
\hline
\end{tabular}

${ }^{\mathrm{a}} \mathrm{CI}$, confidence interval.

${ }^{\mathrm{b}}$ Categories sum to $>100 \%$ as some respondents listed more than one category.

${ }^{\mathrm{c}}$ Practises one type of farming only.

animals, from sick poultry, and from pets. Specialist dairy farmers were more likely than specialist suckler farmers to know what a zoonosis is and, that they or a family member might get an infection from aborting cows/ewes/sows. No significant differences were found between younger and older, nor specialist dairy and specialist suckler farmers in their knowledge of children contracting diarrhoea from being around animals, of the safety of pregnant women helping birthing animals, or of acquiring infections from scouring livestock.

Most respondents accessed information on diseases on the farm from multiple sources. The most common information sources were the veterinary practitioner (913), newspapers (519), Teagasc (the Agriculture and Food Development Authority) (502) and the Department of Agriculture, Food and the Marine (385). Less frequently cited sources were social media (153), agricultural shows (130), the local co-operative (115) and the general practitioner (57).

\section{Hand-washing, use of personal protective equipment (PPE) on the farm}

Farmers' responses to questions on hand washing and their use of PPE are summarised in Table 4, along with comparisons of younger and older and specialist dairy and specialist suckler farmers. Ninety-three per cent of respondents reported washing their hands before eating or smoking while on the farm. Similarly, most reported always washing their hands at the opportunities during the working day about which they were queried. Younger farmers were less likely than older farmers to wash their hands before eating or smoking on the farm, after handling sick animals and, in the morning and evening. However, there was no 
Table 3. Farmers Survey respondents' knowledge of zoonoses and the risk of infection from animals

\begin{tabular}{|c|c|c|c|c|c|c|c|c|c|c|}
\hline \multirow[b]{2}{*}{ Variable } & \multicolumn{2}{|c|}{ All respondents } & \multicolumn{4}{|c|}{ Age group of respondents } & \multicolumn{4}{|c|}{ Specialist ${ }^{\mathrm{a}}$ farming type of respondents } \\
\hline & $N$ & $\begin{array}{l}\text { Rate } \% \\
\left(95 \% \mathrm{CI}^{\mathrm{b}}\right)\end{array}$ & $\begin{array}{l}<45 \text { years } \\
n(\%)\end{array}$ & $\begin{array}{l}45+\text { years } \\
n(\%)\end{array}$ & $\begin{array}{l}\text { Odds ratio } \\
\left(95 \% \mathrm{CI}^{\mathrm{b}}\right)\end{array}$ & $P$ value ${ }^{\mathrm{c}}$ & $\begin{array}{l}\text { Dairy } \\
n(\%)\end{array}$ & $\begin{array}{l}\text { Suckler } \\
n(\%)\end{array}$ & $\begin{array}{l}\text { Odds ratio } \\
\left(95 \% \mathrm{CI}^{\mathrm{b}}\right)\end{array}$ & $P$ value \\
\hline \multicolumn{11}{|c|}{ Might you or family member get an infection from aborting cows/ewes/sows? } \\
\hline Yes & 818 & $78 \cdot 8(75 \cdot 6-80 \cdot 7)$ & $340(77 \cdot 3)$ & $447(82 \cdot 5)$ & \multirow[t]{2}{*}{$0 \cdot 73(0 \cdot 5-1 \cdot 0)$} & \multirow[t]{2}{*}{$0 \cdot 04$} & $217(80 \cdot 7)$ & $161(72 \cdot 9)$ & \multirow[t]{2}{*}{$1 \cdot 6(1 \cdot 1-2 \cdot 4)$} & \multirow[t]{2}{*}{$0 \cdot 04$} \\
\hline No/not sure/missing & 226 & $21 \cdot 6(19 \cdot 3-24 \cdot 3)$ & $100(22 \cdot 7)$ & $95(17 \cdot 5)$ & & & $52(19 \cdot 3)$ & $60(27 \cdot 6)$ & & \\
\hline \multicolumn{11}{|c|}{ Might you or family member get an infection from sick poultry } \\
\hline Yes & 516 & $49 \cdot 4(46 \cdot 4-52 \cdot 4)$ & $258(58 \cdot 6)$ & $238(43 \cdot 9)$ & \multirow{2}{*}{$1 \cdot 8(1 \cdot 1-2 \cdot 3)$} & \multirow{2}{*}{$<0 \cdot 001$} & $130(48 \cdot 3)$ & $105(47 \cdot 5)$ & \multirow{2}{*}{$1 \cdot 0(0 \cdot 7-1 \cdot 5)$} & \multirow{2}{*}{$0 \cdot 86$} \\
\hline No/not sure/missing & 526 & $50 \cdot 6(47 \cdot 4-53 \cdot 6)$ & $182(41 \cdot 4)$ & $304(56 \cdot 1)$ & & & $139(51 \cdot 7)$ & $116(52 \cdot 5)$ & & \\
\hline \multicolumn{11}{|c|}{ Might you or family member get an infection from healthy animals } \\
\hline Yes & 110 & $10 \cdot 5(8 \cdot 8-12 \cdot 6)$ & $59(13 \cdot 4)$ & $46(8 \cdot 5)$ & \multirow[t]{2}{*}{$1 \cdot 7(1 \cdot 1-2 \cdot 5)$} & \multirow[t]{2}{*}{$0 \cdot 01$} & $24(8 \cdot 9)$ & $21(9 \cdot 5)$ & \multirow{2}{*}{$0 \cdot 9(0 \cdot 5-1 \cdot 7)$} & \multirow[t]{2}{*}{$0 \cdot 83$} \\
\hline No/not sure/missing & 934 & $89 \cdot 5(87 \cdot 5-91 \cdot 2)$ & $381(86 \cdot 6)$ & $496(91 \cdot 5)$ & & & $245(91 \cdot 1)$ & $200(90 \cdot 5)$ & & \\
\hline \multicolumn{11}{|l|}{ Might you or family member get an infection from pets } \\
\hline Yes & 498 & $47 \cdot 7(44 \cdot 7-50 \cdot 7)$ & $248(56 \cdot 4)$ & $234(43 \cdot 2)$ & \multirow[t]{2}{*}{$1 \cdot 7(1 \cdot 3-2 \cdot 2)$} & \multirow[t]{2}{*}{$<0 \cdot 001$} & $131(48 \cdot 7)$ & $106(48 \cdot 0)$ & \multirow[t]{2}{*}{$1 \cdot 0(0 \cdot 7-1 \cdot 5)$} & \multirow[t]{2}{*}{$0 \cdot 87$} \\
\hline No/not sure/missing & 546 & $52 \cdot 3(49 \cdot 3-55 \cdot 3)$ & $192(43 \cdot 6)$ & $308(56 \cdot 8)$ & & & $138(51 \cdot 3)$ & $115(52 \cdot 0)$ & & \\
\hline \multicolumn{11}{|l|}{ What is a zoonosis? } \\
\hline A disease a person can pick up from an animal & 346 & $33 \cdot 1(30 \cdot 3-36 \cdot 1)$ & $194(44 \cdot 1)$ & $143(26 \cdot 4)$ & \multirow[t]{2}{*}{$2 \cdot 2(1 \cdot 7-2 \cdot 9)$} & \multirow[t]{2}{*}{$<0 \cdot 001$} & $95(35 \cdot 3)$ & $57(25 \cdot 8)$ & \multirow[t]{2}{*}{$1 \cdot 6(1 \cdot 1-2 \cdot 3)$} & \multirow[t]{2}{*}{0.02} \\
\hline Incorrect/don't know/missing & 698 & $66 \cdot 9(64 \cdot 0-70 \cdot 0)$ & $246(55 \cdot 9)$ & $399(73 \cdot 6)$ & & & $174(64 \cdot 7)$ & $164(74 \cdot 2)$ & & \\
\hline
\end{tabular}

${ }^{\mathrm{a}}$ Practises one type of farming only.

${ }^{\mathrm{b}} \mathrm{CI}$, Confidence interval.

${ }^{\mathrm{c}} P$ value for Pearson $\chi^{2}$. 
Table 4. Farmers Survey respondents' hand washing practices and use of personal protective equipment

\begin{tabular}{|c|c|c|c|c|c|c|c|c|c|c|}
\hline \multirow[b]{2}{*}{ Variable } & \multicolumn{2}{|c|}{ All respondents } & \multicolumn{4}{|c|}{ Age group of respondents } & \multicolumn{4}{|c|}{ Specialist ${ }^{\mathrm{a}}$ farming type of respondents } \\
\hline & $N$ & $\begin{array}{l}\text { Rate } \% \\
\left(95 \% \mathrm{CI}^{\mathrm{b}}\right)\end{array}$ & $\begin{array}{l}<45 \text { years } \\
n\end{array}$ & $\begin{array}{l}45+\text { years } \\
n\end{array}$ & $\begin{array}{l}\text { Odds ratio } \\
\left(95 \% \mathrm{CI}^{\mathrm{b}}\right)\end{array}$ & $P$ value $^{\mathrm{c}}$ & $\begin{array}{l}\text { Dairy } \\
n\end{array}$ & $\begin{array}{l}\text { Suckler } \\
n\end{array}$ & $\begin{array}{l}\text { Odds ratio } \\
\left(95 \% \mathrm{CI}^{\mathrm{b}}\right)\end{array}$ & $P$ value $^{\mathrm{c}}$ \\
\hline \multicolumn{11}{|c|}{ When on the farm, do you wash your hands before eating/smoking? } \\
\hline Yes & 944 & $96 \cdot 0(94 \cdot 2-96 \cdot 8)$ & $401(93 \cdot 9)$ & $492(97 \cdot 0)$ & $0 \cdot 47(0 \cdot 3-0 \cdot 9)$ & 0.02 & $244(94 \cdot 9)$ & $202(95 \cdot 3)$ & $0 \cdot 9(0 \cdot 4-2 \cdot 2)$ & $0 \cdot 86$ \\
\hline No & 43 & $4 \cdot 0(3 \cdot 3-5 \cdot 8)$ & $26(6 \cdot 1)$ & $15(3 \cdot 0)$ & & & $13(5 \cdot 1)$ & $10(4 \cdot 7)$ & & \\
\hline \multicolumn{11}{|c|}{ Do you wash your hands after handling sick animals? } \\
\hline Always & 830 & $88.9(86 \cdot 7-90 \cdot 7)$ & $338(83 \cdot 7)$ & $435(92 \cdot 0)$ & $0 \cdot 45(0 \cdot 3-0 \cdot 7)$ & $<0 \cdot 001$ & $216(88 \cdot 2)$ & $169(91 \cdot 3)$ & $0 \cdot 71(0 \cdot 4-1 \cdot 3)$ & $0 \cdot 29$ \\
\hline Sometimes/never & 104 & $11 \cdot 1(9 \cdot 3-13 \cdot 3)$ & $66(16 \cdot 3)$ & $38(8 \cdot 0)$ & & & $29(11 \cdot 8)$ & $16(8 \cdot 6)$ & & \\
\hline \multicolumn{11}{|c|}{ Do you wash your hands in the morning and evening? } \\
\hline Always & 689 & $85 \cdot 7(83 \cdot 1-88 \cdot 0)$ & $306(82 \cdot 0)$ & $351(88 \cdot 9)$ & $0.57(0.4-0.9)$ & 0.007 & $186(87 \cdot 8)$ & $130(86 \cdot 1)$ & $1 \cdot 2(0 \cdot 6-2 \cdot 1)$ & $0 \cdot 6$ \\
\hline Sometimes/never & 115 & $14 \cdot 3(12 \cdot 1-16 \cdot 9)$ & $67(18)$ & $44(11 \cdot 1)$ & & & $26(12 \cdot 2)$ & $21(13 \cdot 9)$ & & \\
\hline \multicolumn{11}{|c|}{ Do you wear gloves when working? } \\
\hline Yes & - & - & $381(87 \cdot 0)$ & $471(87 \cdot 8)$ & $0 \cdot 93(0 \cdot 6-1 \cdot 4)$ & $0 \cdot 74$ & $260(97 \cdot 0)$ & $177(81 \cdot 6)$ & $7 \cdot 4(3 \cdot 4-16 \cdot 1)$ & $<0 \cdot 001$ \\
\hline Sometimes/never & - & - & $57(13 \cdot 0)$ & $66(12 \cdot 2)$ & & & $8(3 \cdot 0)$ & $40(18 \cdot 4)$ & & \\
\hline \multicolumn{11}{|c|}{ When do you remove your boiler suit/wet gear? } \\
\hline Every time I enter the home & 394 & $75(71 \cdot 6-79 \cdot 0)$ & $196(58 \cdot 5)$ & $184(46 \cdot 0)$ & $1 \cdot 7(1 \cdot 2-2 \cdot 2)$ & $0 \cdot 001$ & $117(58 \cdot 5)$ & $80(44 \cdot 0)$ & $1 \cdot 8(1 \cdot 2-2 \cdot 7)$ & $0 \cdot 004$ \\
\hline Less frequently & 128 & $25(21 \cdot 0-28 \cdot 4)$ & $139(14 \cdot 5)$ & $216(54 \cdot 0)$ & & & $83(41 \cdot 5)$ & $102(56 \cdot 0)$ & & \\
\hline
\end{tabular}

${ }^{\mathrm{a}}$ Practises one type of farming only.

${ }^{\mathrm{b}} \mathrm{CI}$, confidence interval.

${ }^{\mathrm{c}} P$ value for Pearson $\chi^{2}$. 


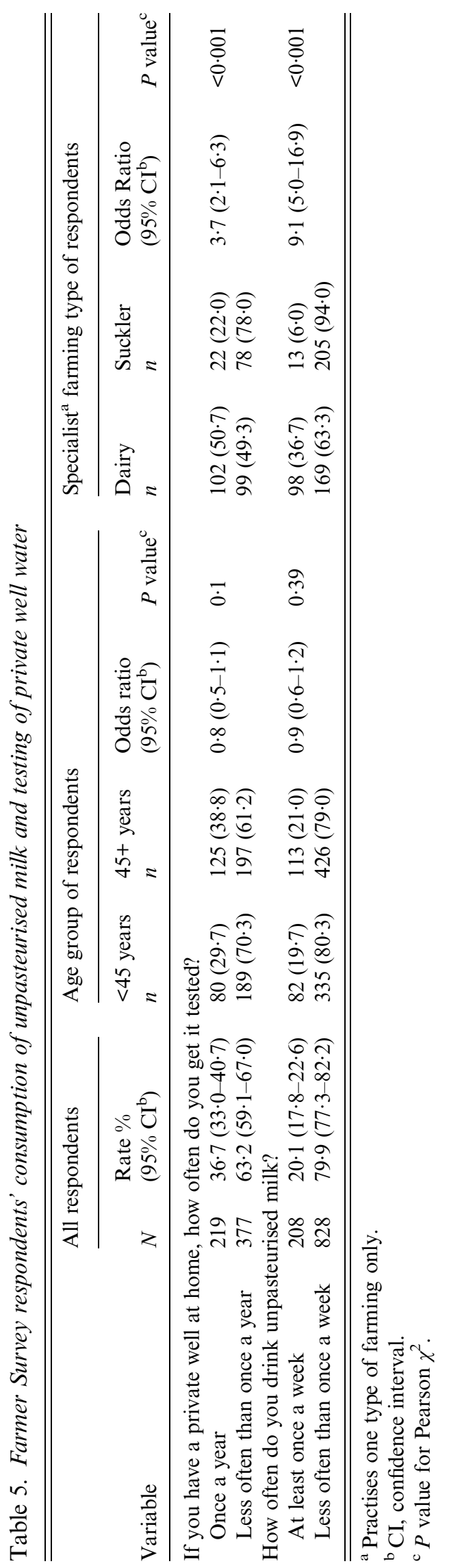

significant difference in washing hands before meals between younger and older farmers. No significant differences were found in hand-washing opportunities taken between; specialist dairy and specialist suckler farmers; those who knew what a zoonosis is and those who did not; and those who knew that children can get vomiting and diarrhoea from being around animals and those who did not.

Farmers were asked about disposable glove usage during the working day (assisting animals giving birth, milking, looking after stock, and for other activities). Many respondents wear disposable gloves for more than one of the listed tasks, while 125 stated that they rarely or never wear disposable gloves. Specialist dairy farmers were more likely than specialist suckler farmers to wear gloves during the working day. No significant differences were found in glove-wearing opportunities between younger and older farmers; those who knew what a zoonosis is and those who did not; and those who knew that children can get vomiting and diarrhoea from being around animals and those who did not.

Three quarters of survey respondents (767) completed the questions on the removal of personal protective clothing. Of these, a third (245) reported that they did not wear a boiler suit/wet gear while working. Of those who did wear a boiler suit/wet gear, almost one-quarter reported not removing the boiler suit/ wet gear every time they entered the family home. Younger and specialist dairy (as opposed to specialist suckler) farmers were more likely to do.

\section{Drinking-water source to the home and consumption of unpasteurised milk}

Responses to questions on farmers' home drinkingwater source and their consumption of unpasteurised milk are summarised in Table 5. Almost three-quarters use a private drinking-water source; a private well or a private group water scheme (a shared private source, that is treated and managed privately) (Table 1). When private well-water users were asked how often they had their well-water tested, $37 \%$ reported having it tested annually while $63 \%$ reported having it tested less often than once a year. Specialist dairy farmers were more likely than specialist suckler farmers to test their well water annually. No significant differences were found in frequency of well-water testing between younger and older farmers; those who knew what a zoonosis is and those who did not; and those who knew that children can get vomiting and diarrhoea from being around animals and those who did not. 


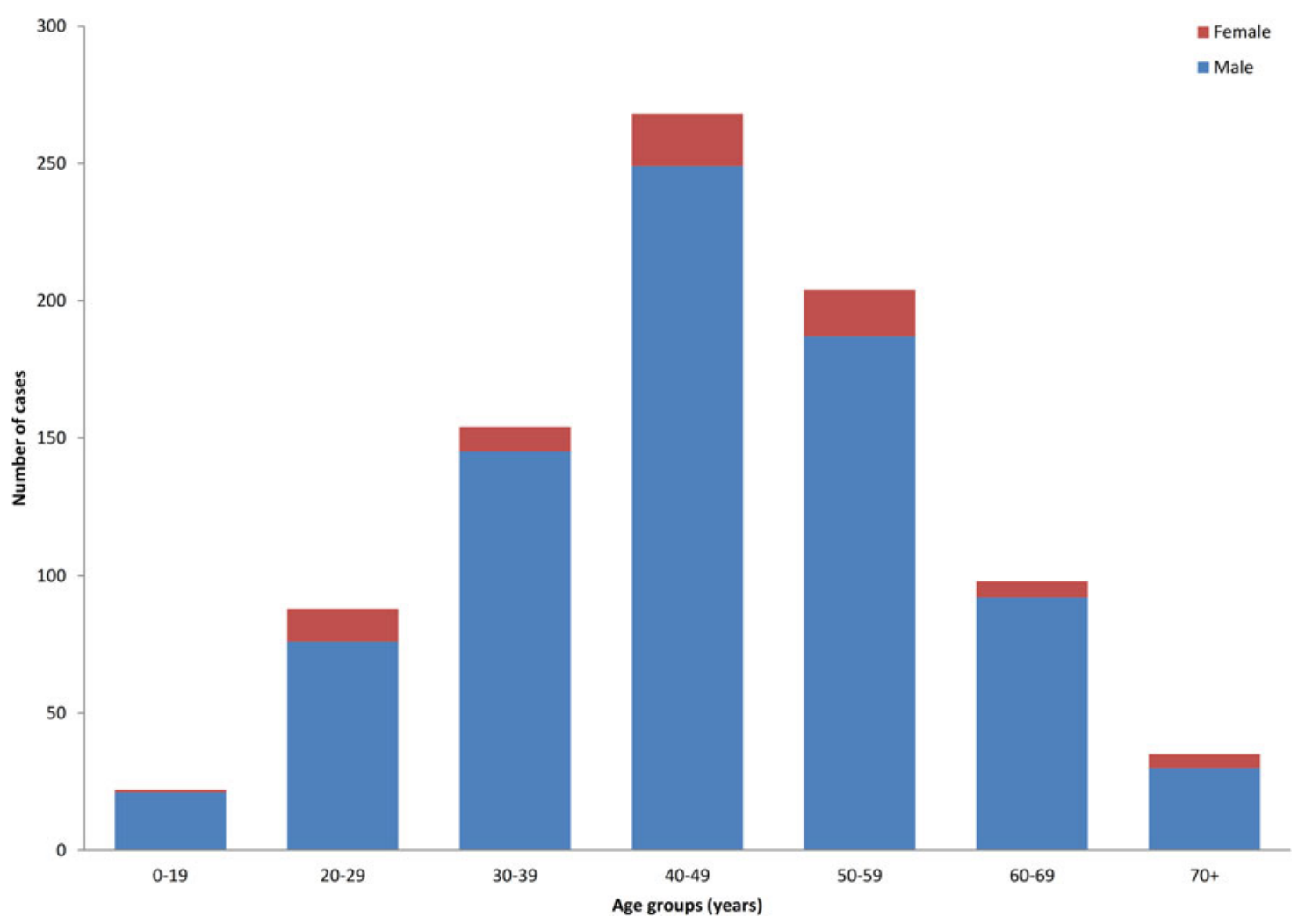

Fig. 1. Gender and age groups of Farmers' Survey respondents, $2015(n=869)$.

One-fifth (208) of all farmers and two-fifths (171) of dairy farmers reported drinking unpasteurised milk at least once a week (Fig. 2). Specialist dairy farmers were nine times more likely to report drinking unpasteurised milk at least once a week than specialist suckler farmers were. No significant differences were found in consumption of unpasteurised milk between younger and older farmers; those who knew what a zoonosis is and those who did not; and those who knew that children can get vomiting and diarrhoea from being around animals and those who did not.

\section{DISCUSSION}

Despite the well-recognised human disease risks associated with farm animals and the farming environment, a national survey of this type is, to our knowledge, unique. A review of the literature suggests that this subject has attracted little research.

This study shows considerable variation in respondents' knowledge. The farmers were well informed about the risk of infection from aborting and birthing animals, but were less aware that scouring stock, sick poultry and pets were potential infection sources, and that children can contract infectious gastroenteritis from being around animals. Alarmingly, only 10\% of farmers identified healthy animals as a possible infection source. A small survey of ruminant farm families in the USA [21] found that $70 \%$ of farmers did not think, or were unsure that, their knowledge of zoonotic diseases was sufficient to protect themselves or their family members. A Canadian study involving patients attending two urban physician practices found only $24 \%$ were aware that infectious diarrhoea could be transmitted from pets to humans [22]. Since awareness of the risk of infection from zoonoses is a prerequisite to infection prevention, it is concerning that farmers' knowledge of the sources of zoonotic infections is limited.

The age groups $<45$ years and $45+$ years were used as an indicator having received vocational agricultural education. These age groups were chosen because in the early 1990s, exemptions from acquisition taxes and eligibility to receive farming grants in Ireland were linked to farmers having a certified vocational qualification in farming called 'The Green Cert' [23]. Therefore, it would be expected that farmers who came of age since the early 1990s, i.e. those under the age of 45 years, would be more likely to have formal farming education than those over 45 years. The 


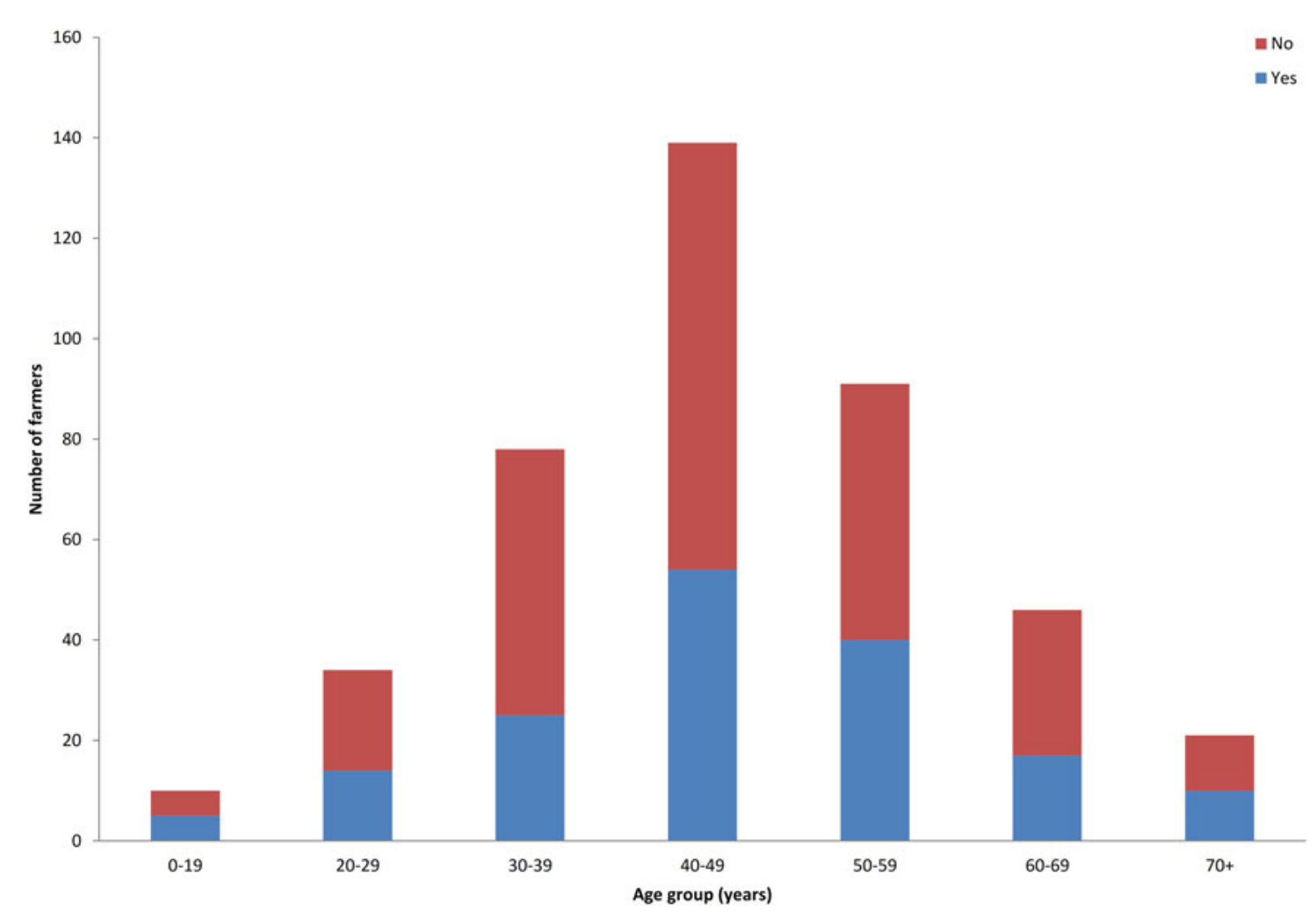

Fig. 2. Age groups of dairy farmers and their consumption of unpasteurised milk $(n=419)$

category specialist dairy farming was used as an example of a highly regulated farming type where the farmer has a lot of interaction with animals, while the category of specialist suckler farmer was used as an example of a farming type with minimal regulation and where the farmer has little interaction with animals. Knowing that children can get diarrhoea from being around animals and knowing what a zoonosis is were used as two indicators of having an awareness of zoonoses and the risk of infections from animals.

Only one-third of survey respondents could correctly (from three possible options) define a zoonosis as 'a disease that a person can pick up from animals'. A study of a university community in Nigeria [24] found that only $19 \%$ those questioned had heard of the term 'zoonoses'. This is a reminder to those providing infection prevention and control advice to farmers to use plain English and to avoid of use of medical terms.

Our results indicate that veterinarians are well placed, within the One Health approach, to help in the prevention of zoonoses. This would include providing specific risk-reduction advice about appropriate vaccinations, parasite preventatives and the use of PPE.

Approximately $40 \%$ of dairy farmers consume unpasteurised milk once, or more often than once a week. It is not surprising that dairy farmers are more likely than suckler farmers to do so. In 1998, a prevalence study indicated that $84 \%$ of Irish dairy farming families consumed unpasteurised milk [25], while smaller studies since have put the figure at $72 \%$ [26] and $20 \%$ [27]. While our study may represent a real change in the percentage of dairy farmers consuming raw milk, or the difference may be due to sampling (farmers present with animals to the RVL for diagnosis, and to institute control measures on the farm, and are, therefore, possibly more conscious of health risks on the farm), the results indicate that dairy farmers continue to potentially expose themselves and their families, unnecessarily, to pathogenic organisms in their milk.

In Ireland, studies have shown Listeria monocytogenes $[28,29]$ and VTEC or $v t$ gene [27, 30] contamination of the dairy farm environment and raw milk from bovine, caprine and ovine herds/flocks. In Ireland from 2013 to $2015,2 \cdot 7 \%$ of all cases of VTEC notified on the Irish central repository, Computerised Infectious Disease Reporting (CIDR) System, reported that they consumed unpasteurised milk or cheese [31]. In an outbreak affecting cattle and humans on an Irish dairy farm, 
bovine tuberculosis had a significant impact on the health of two young children who drank unpasteurised milk [32].

Hegarty et al. [26] cited the main reasons for the continued consumption of raw milk as confidence in its safety, cost, convenience, taste and tradition. They also found that farmers believed that if routine tests of milk for total and somatic cell counts and brucellosis are 'clear', and then the milk is safe to use. The fact that their animals were not showing clinical signs of disease afforded them further confidence in the safety of the milk [26]. In our survey, only $10 \%$ of farmers were aware that it is possible to contract disease from apparently healthy animals. It is healthy animals that contribute milk to the bulk tank, from which unpasteurised milk would be taken, giving a false sense of security to the consumers of unpasteurised milk.

Fifty-nine per-cent of farmers said that a private well was their only source $(55 \%)$, or one of their sources $(4 \%)$ of drinking water. Water charges were introduced in Ireland in 2014 (since suspended), and this may have had an impact on private well ownership since then. There was a national census in 2016, and a comparative figure to the $48 \%$ cited by the CSO for 2011 [14] will be available when these data are published. It is not surprising that a high proportion of farmers have private wells, but does illustrate a risk to which farmers, their families, and visitors to their homes may be exposed if the well is not properly constructed, protected and tested.

It is recommended that private wells, while not regulated (European Communities Drinking Water Regulations 2014 [33]), should comply with the water quality standards [34], which have been set in order to protect human health. Moreover, farmers who are primary producers and food business operators (e.g. dairy farmers) are obliged under European Communities Hygiene of Foodstuffs regulations [23] to use potable water that complies with the drinking-water regulations [33]. Our results indicate that guidance on safe construction and protection of private wells $[16,35]$ needs to be targeted at the agricultural community. In this survey, almost $20 \%$ of those with a private well at home had never had it tested and $45 \%$ have their well tested less often than annually. The IGI states that there is a need for standards to regulate the drilling, construction, testing and sealing of water wells [16].

The risk to human health to people working and visiting farms, through exposure to animals and the farm environment, is real [36-38]. The risk can be reduced by taking practical measures to reduce exposure to zoonotic agents, e.g. proper use of PPE, and taking practical measures to mitigate against infection arising from exposure, e.g. hand washing. A reassuring $93 \%$ of respondents reported washing their hands before eating or smoking while on the farm. The impact of hand hygiene in reducing infectious disease risks among the farming community could be increased by convincing people to wash their hands correctly, and at the correct time [38].

A large number of respondents wore gloves when carrying out particular tasks. The benefits of gloves when used and disposed of properly are well documented [8]. Unfortunately, this survey did not establish whether farmers are aware that wearing gloves is not a substitute for hand washing.

Thirty per cent of respondents did not wear a boiler suit/wet gear, and of those who did, one quarter did not remove these potentially contaminated garments when entering the family home. The Food Safety Authority of Ireland recognises this risk and recommends that farm work clothes or footwear are not worn in the home because they can spread E. coli [39].

Even though older farmers are less likely to be aware of the science, they are more likely to carry out basic practices (hand-washing) for disease prevention. Younger farmers are more likely to know that they can catch an infection from healthy animals, from sick poultry, and from pets. However, older farmers are more likely to wash their hands before eating or smoking on the farm; after handling sick animals; and in the morning and evening. Specialist dairy farmers are more likely than specialist suckler farmers to know what a zoonosis is and, that they or a family member might get an infection from aborting cows/ewes/sows. Specialist dairy farmers are more likely than specialist suckler farmers to have their well water tested annually and to wear gloves while working (they are primary producers and obliged to adhere to European Communities Hygiene of Foodstuffs regulations [40]).

In terms of behaviour and knowledge, no significant differences were found in hand-washing/glovewearing opportunities between those who knew what a zoonosis is and those who did not; and those who knew that children can get vomiting and diarrhoea from being around animals and those who did not.

As the respondents are farmers who attended RVLs to investigate ill-health in their animals, the sample may be biased in favour of farmers with more knowledge of zoonoses and infection prevention practices. Therefore, it is possible that our study may over estimate farmers' knowledge of zoonoses and infection 
prevention practices. The results illustrate the need for further education, in plain language, to increase the awareness of potential biohazards on farms, and practical measures that can be taken to mitigate the risk of zoonotic infection. The fact that most farmers accessed information on diseases on the farm from multiple sources, suggests that a multi-faceted, One Health approach to health protection in the farming community is merited. Evidence shows that building partnerships with agencies providing services in rural communities and trusted sources of information for the target population (e.g. farmer and country women's organisations, government departments, financial organisations, etc.), to provide information and training are effective ways of engaging with health promotion activities in farming and rural communities [41-43].

\section{ACKNOWLEDGEMENTS}

We are grateful to Ms Patricia Dunphy, Serological Assistant at Kilkenny Regional Veterinary Laboratory, who inputted the survey data onto our database. We would also like to thank the laboratory directors and clerical staff at Athlone, Cork, Dublin, Kilkenny, Limerick and Sligo Regional Veterinary Laboratories who facilitated the collection the survey data, and the members of the South East Regional Zoonoses Committee for supporting this work.

\section{DECLARATION OF INTEREST}

None.

\section{DISCLAIMERS}

None.

\section{REFERENCES}

1. Central Statistics Office. Census of Agriculture 2010 Final Results. Dublin: The Stationary Office, 2012.

2. Acha PN, Szyfres B. Zoonoses and Communicable Diseases Common to Man and Animals, 3rd edn. Washington, DC: Pan American Health Organisation, 2002, vol. 1, p. ix.

3. Grant S, Olsen CW. Preventing zoonotic diseases in immunocompromised persons: the role of physicians and veterinarians. Emerging Infectious Disesases 1999; 5: 159-163.

4. Gerrard CE. Farmers' occupational health: cause for concern, cause for action. Journal of Advanced Nursing 1998; 28: 155-163.
5. Centers for Diesase Control and Prevention. One Health (http://www.cdc.gov/onehealth/). Accessed 30 September 2016.

6. Bender JB, Heuston W, Osterholm M. Recent animal disease outbreaks and their impact on human populations. Journal of Agromedicine 2006; 11: 841-847.

7. Steinmuller N, et al. Outbreaks of enteric disease associated with animal contact: not just a foodborne problem anymore. Clinical Infectious Diseases 2006; 43: 1596-1602.

8. Williams CJ, et al. Compendium of veterinary standard precautions for zoonotic disease prevention in veterinary personnel: National Association of State Public Health Veterinarians: Veterinary Infection Control Committee 2015. Journal of the American Veterinary Medicine Association 2015; 247: 1252-1277.

9. Bloomfield SF, et al. The effectiveness of hand hygiene procedures in reducing the risks of infections in home and community settings including handwashing and alcohol-based hand sanitizers. American Journal of Infection Control 2007; 35: S27-64.

10. Centers for Diesase Control and Prevention. Food Safety and Raw Milk (http://www.cdc.gov/foodsafety/rawmilk/ raw-milk-index.html). Accessed 30 September, 2016.

11. Oliver SP, et al. Food safety hazards associated with consumption of raw milk. Foodborne Pathogens and Disease 2009; 6: 793-806.

12. Quigley L, et al. The complex microbiota of raw milk. FEMS Microbiology Reviews 2013; 37: 664-698.

13. Mungai EA, Behravesh CB, Gould LH. Increased outbreaks associated with nonpasteurized milk, United States, 2007-2012. Emerging Infectious Diseases 2015; 21: 119-122.

14. Central Statistics Office. Census 2011, Profile 4, The Roof Over our Heads -Housing in Ireland. Dublin: The Stationary Office, 2012.

15. Environmental Protection Agency. Drinking water (http://www.epa.ie/water/dw/). Accessed 30 September, 2016.

16. Institute of Geologists of Ireland. Guidelines for Drilling Wells for Private Water Supplies (http://igi.ie/assets/files/ Water $\% 20$ Well $\% 20$ Guidelines/Summary.pdf). Accessed 30 September 2016.

17. Irish Statute Book. S.I. No. 390/1981 - Infectious Diseases Regulations 1981. (http://www.irishstatutebook.ie/eli/1981/ si/390/made/en/print). Accessed 30 September 2016.

18. Health Protection Surveillance Centre. VTEC and Water (http://www.hpsc.ie/A-Z/Gastroenteric/VTEC/ VTECandwater/). Accessed 30 September, 2016.

19. Health Protection Surveillance Centre. Annual Epidemiological Report 2014. Dublin: Health Protection Surveillance Centre, 2015.

20. Environmental Protection Agency. Ireland's Environment. Wexford: Environmental Protection Agency, 2004.

21. Kersting AL, et al. Zoonoses and the physicians' role in educating farming patients. Journal of Agromedicine 2009; 14: 306-311.

22. Stull JW, et al. Household knowledge, attitudes and practices related to pet contact and associated zoonoses in Ontario, Canada. BioMed Central Public Health 2012; 12: 553. 
23. Teagasc. Green Cert (https://www.teagasc.ie/education/ teagasc-colleges/botanic-gardens/green-cert/). Accessed 18 May 2017.

24. Awosanya EJ, Akande HO. Animal health care seeking behavior of pets or livestock owners and knowledge and awareness on zoonoses in a university community. Veterinary World 2015; 8: 841-847.

25. Buckley J, McRory F, O'Mahony P. On Farm Study of Consumption of Unpasteurised Milk. Dublin: Food Safety Authority of Ireland, 1998.

26. Hegarty H, et al. Continued raw milk consumption on farms: why? Communicable Disease and Public Health 2002; 5: 151-156.

27. Lynch MJ, et al. Surveillance of verocytotoxigenic Escherichia coli in Irish bovine dairy herds. Zoonoses and Public Health 2012; 59: 264-271.

28. Fox E, et al. Listeria monocytogenes in the Irish Dairy Farm Environment. Journal of Food Protection 2009; 72: $1450-1456$.

29. Hunt K, et al. A case of bovine raw milk contamination with Listeria monocytogenes. Veterinary Ireland Journal 2013; 3: 1-5.

30. Murphy M, et al. Surveillance of dairy production holdings supplying raw milk to the farmhouse cheese sector for Escherichia coli $\mathrm{O} 157, \mathrm{O} 26$ and O111. Zoonoses and Public Health 2007; 54: 358-365.

31. Health Protection Surveillance Centre. Computerised Infectious Disease Reporting (http://www.hpsc.ie/ CIDR/). Accessed 29 December 2016.

32. Doran P, et al. An outbreak of tuberculosis affecting cattle and people on an Irish dairy farm, following the consumption of raw milk. Irish Veterinary Journal 2009; 62: 390.

33. Environmental Protection Agency. Protecting Your Private Well (http://www.epa.ie/water/dw/hhinfo/protprivwell/). Accessed 30 September 2016.

34. Irish Statute Book. S.I. No 122/2014 European Union (Drinking Water) Regulations 2014 (http://www. irishstatutebook.ie/eli/2014/si/122/made/en/pdf). Accessed 30 September 2016.

35. Environmental Protection Agency. EPA Drinking Water Advice Note - Advice Note No. 14. Bore Hole Construction and Well Head Protection (http://www. epa.ie/pubs/advice/drinkingwater/advicenote14.html). Accessed 30 September 2016.

36. Sayers GM, et al. Cryptosporidiosis in children who visited an open farm. Communicable Disease Report. CDR Review 1996; 6: R140-R144.

37. Rowell S, et al. An outbreak of Shiga toxin-producing Escherichia coli serogroup O157 linked to a lambfeeding event. Epidemiology and Infection 2016; 144: 2494-2500.

38. Independent Investigation Committee. Review of the Major Outbreak of E. coli O157 in Surrey, 2009. London: Health Protection Agency, 2010.

39. Food Safety Authority of Ireland. E. coli - How to Reduce the Risk from your Farm. Dublin: Food Safety Authority of Ireland, 2012.

40. Official Journal of the European Union. Regulation (EC) No. 852/2004 of the European Parliament and of the Council of 29 April 2004 on the Hygiene of Foodstuffs (http://eur-lex.europa.eu/legal-content/EN/TXT/PDF/? uri=CELEX:32004R0852\&qid $=1485347155378 \&$ from $=$ EN). Accessed 30 September 2016.

41. Frager L, et al. Partnerships to promote mental health of NSW farmers: The New South Wales farmers blueprint for mental health. Australian Journal of Rural Health 2008; 16: 170-175.

42. Ehlers JJ, Graydon PS. Noise-induced hearing loss in agriculture: creating partnerships to overcome barriers and educate the community on prevention. Noise and Health 2011; 13: 142-146.

43. Richardson N, et al. Staying fit for farming - a health booklet designed for Irish farmers. Journal of Agromedicine 2015; 20: 381-385. 